\title{
Chromatin replication and epigenome maintenance
}

Alabert, Constance; Groth, Anja

Published in:

Nature Reviews. Molecular Cell Biology

DOI:

$10.1038 / \mathrm{nrm} 3288$

Publication date:

2012

Document version

Peer reviewed version

Citation for published version (APA):

Alabert, C., \& Groth, A. (2012). Chromatin replication and epigenome maintenance. Nature Reviews. Molecular Cell Biology, 13(3), 153-67. https://doi.org/10.1038/nrm3288 
BOX1. The eukaryotic replisome

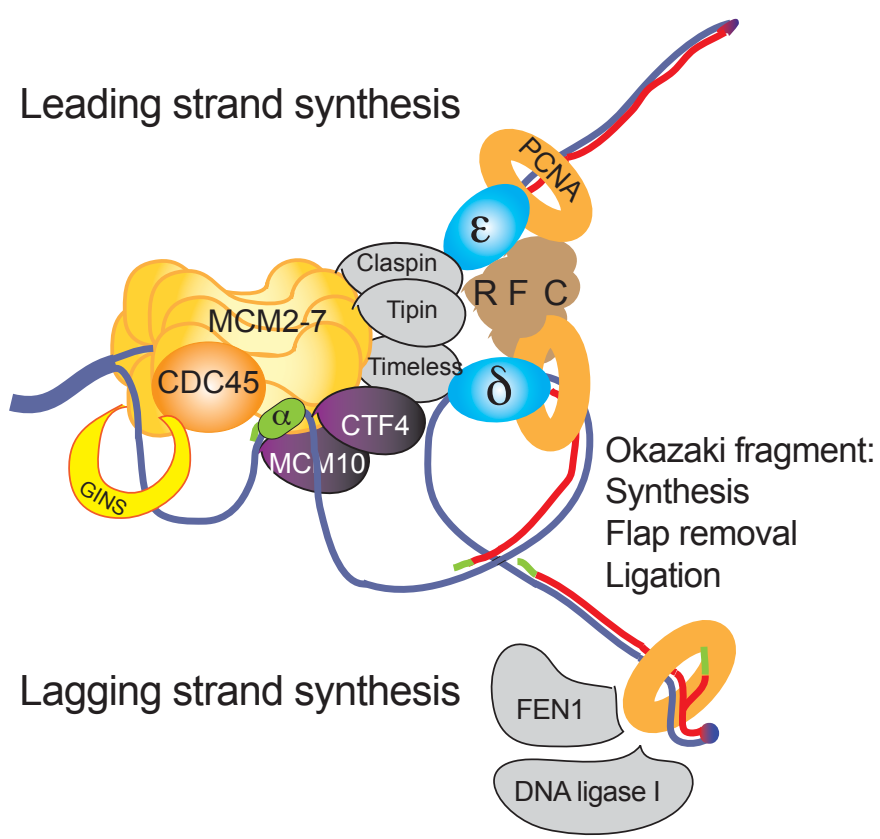


Figure 1. Initiation control

a

Early replicating domain

Late replicating domain

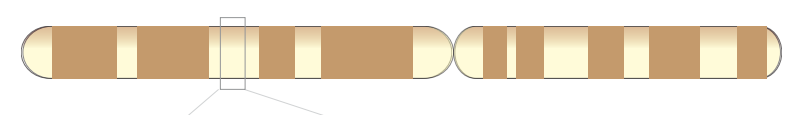

iming domain

Size $\backsim 200 \mathrm{~kb}$ to $5 \mathrm{Mb}$

Replication domain

cluster of 5 to 10 active origins Size $\backsim 1 \mathrm{Mb}$

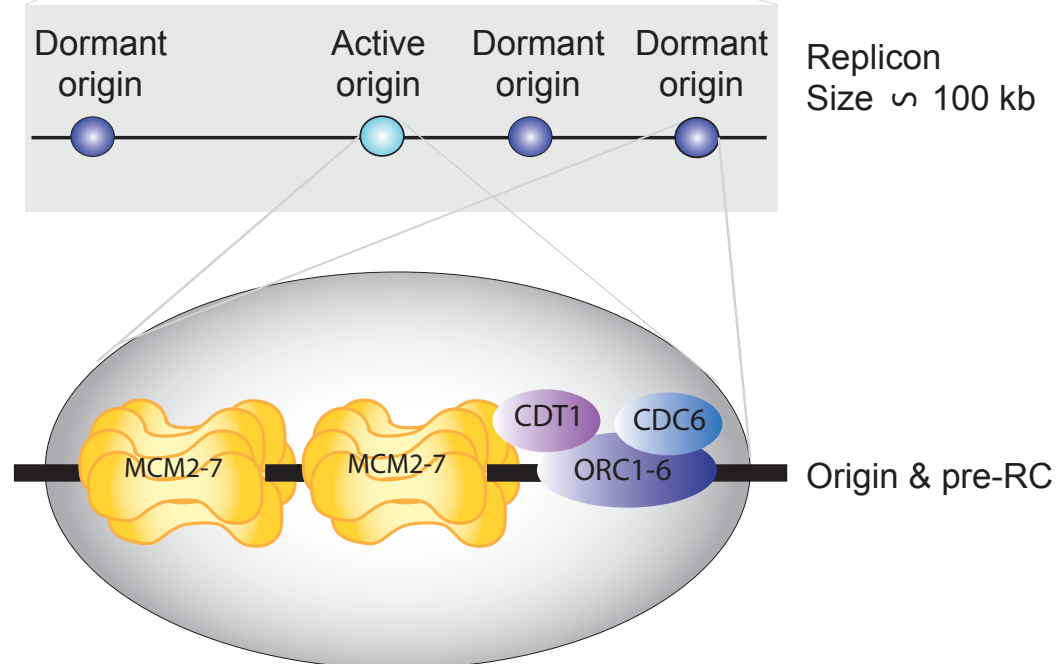

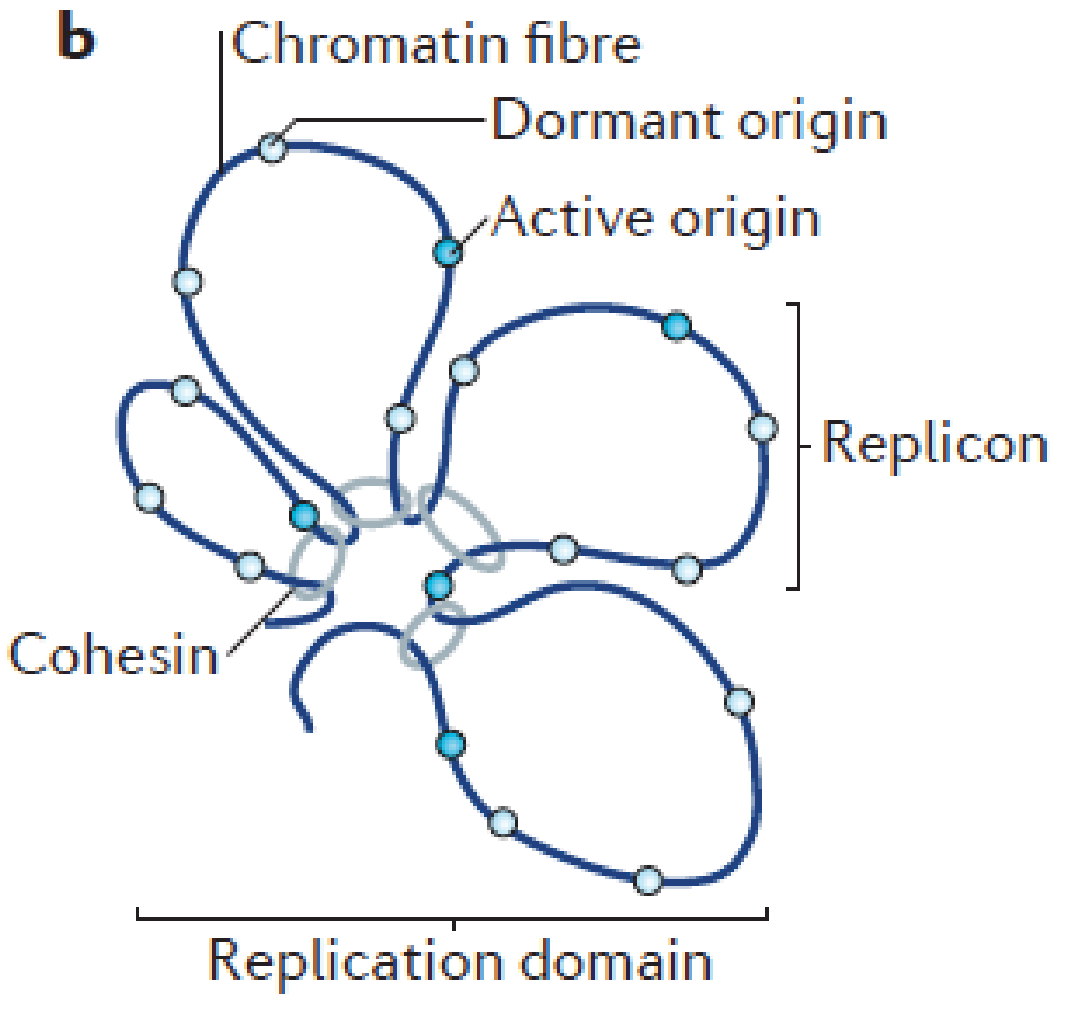


Figure 2. Chromatin disassembly

a

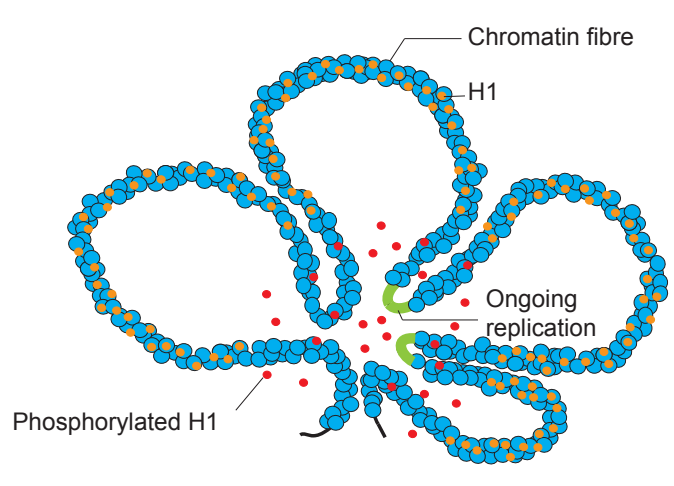

b

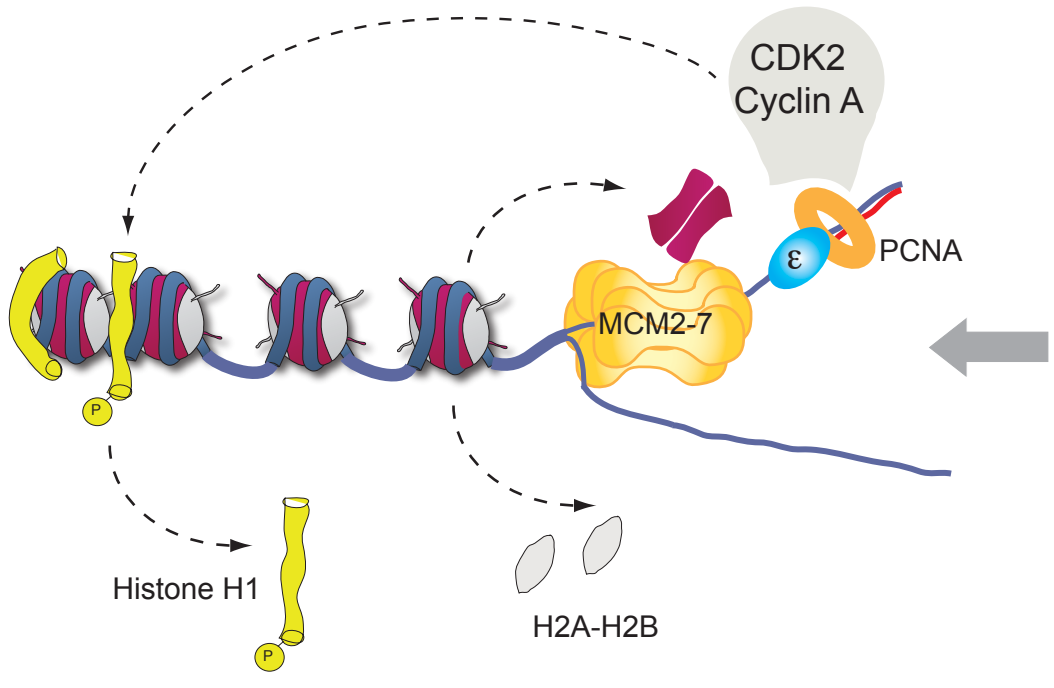

H3-H4 dimer

Polymerase 


\section{Figure 3}

a

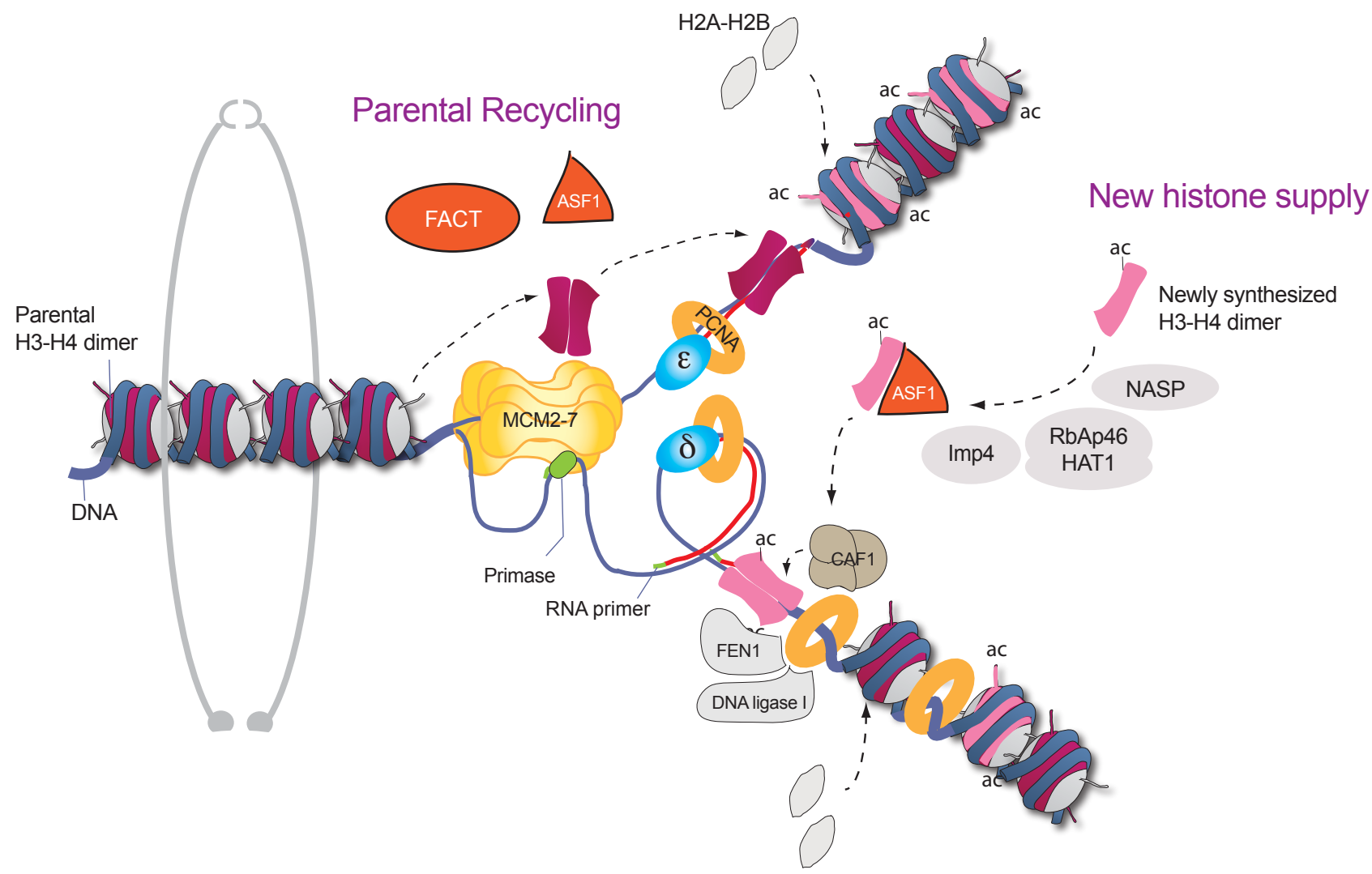

b

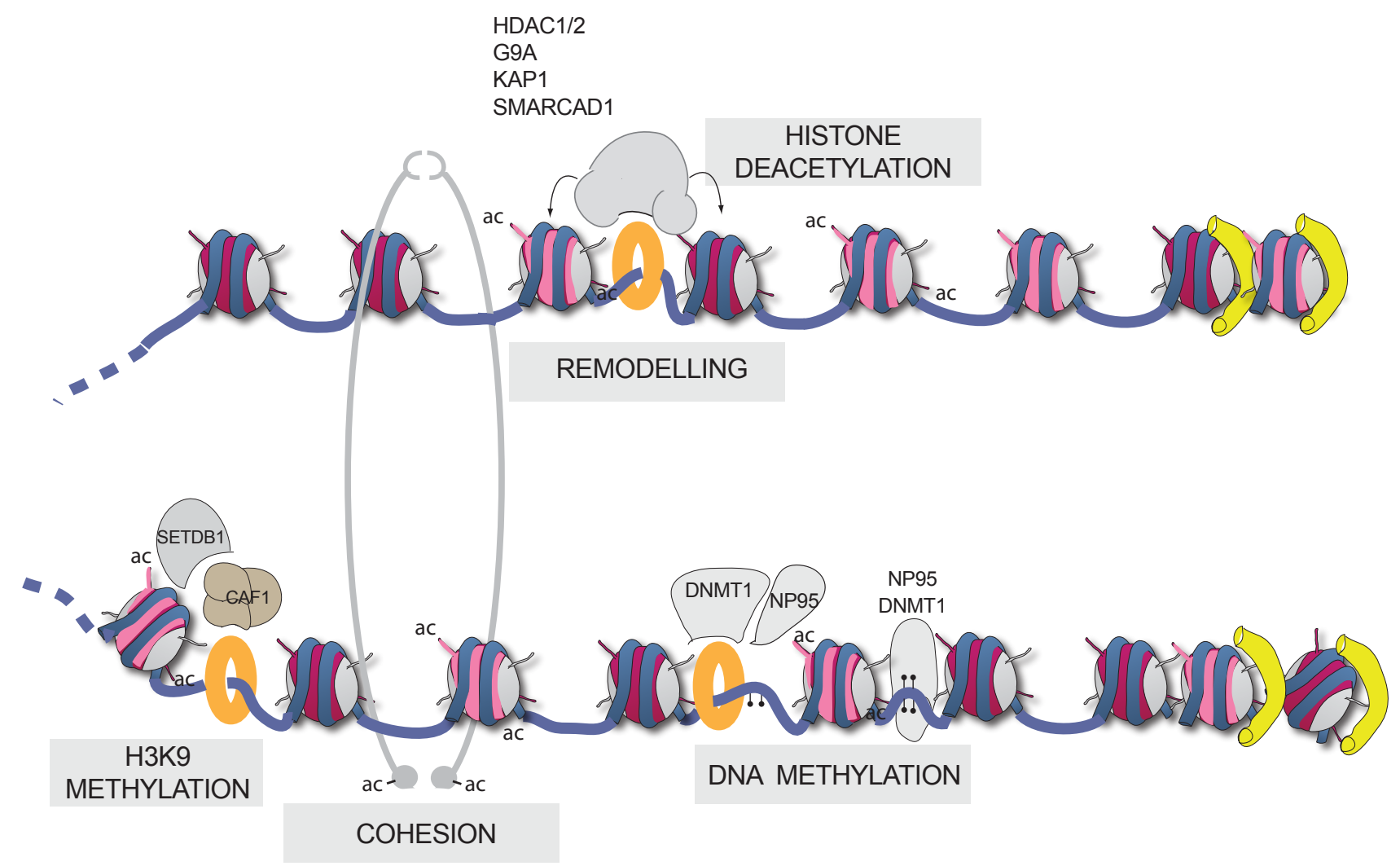

HISTONE

ACETYLATION

$\mathrm{H} 1$

BINDING

DNA 
Figure 4. Oscillation of histone methylation during the cell cycle

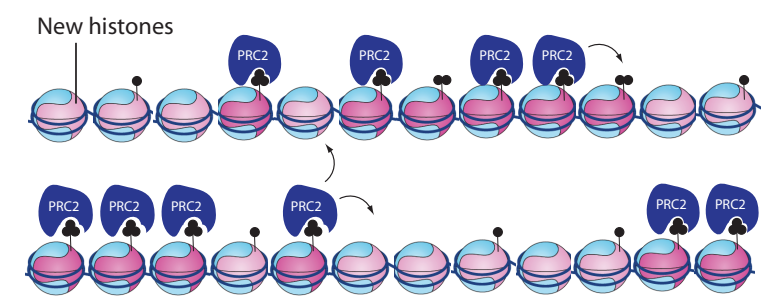

2. Post replicative sister chromatids

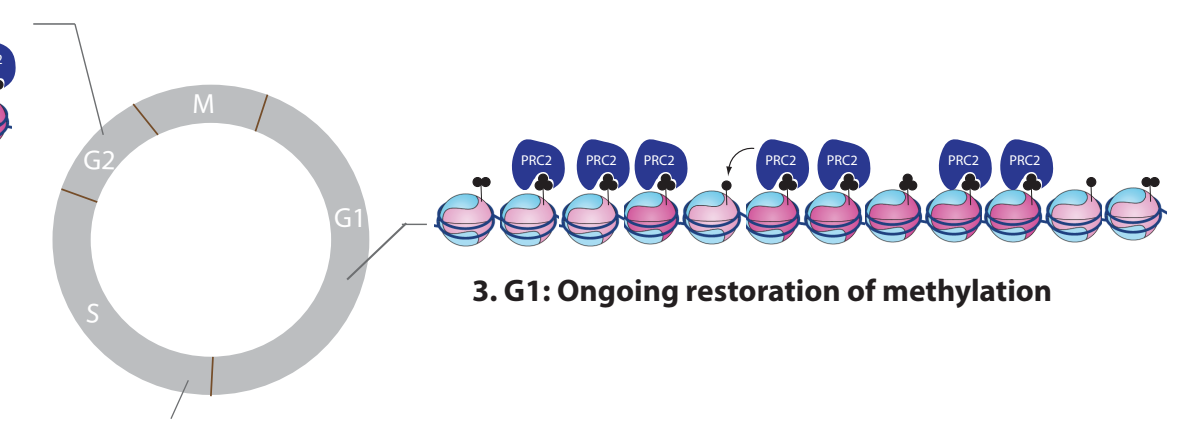

Parental histones

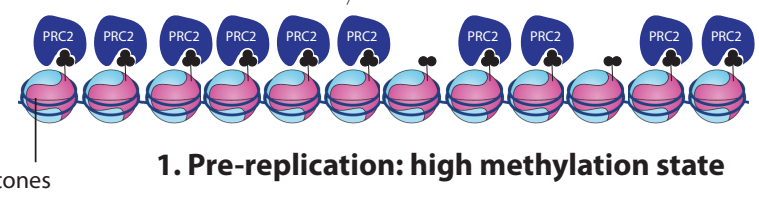

• H3K27me1 
Figure 5. A vicious circle of (epi)genome instability

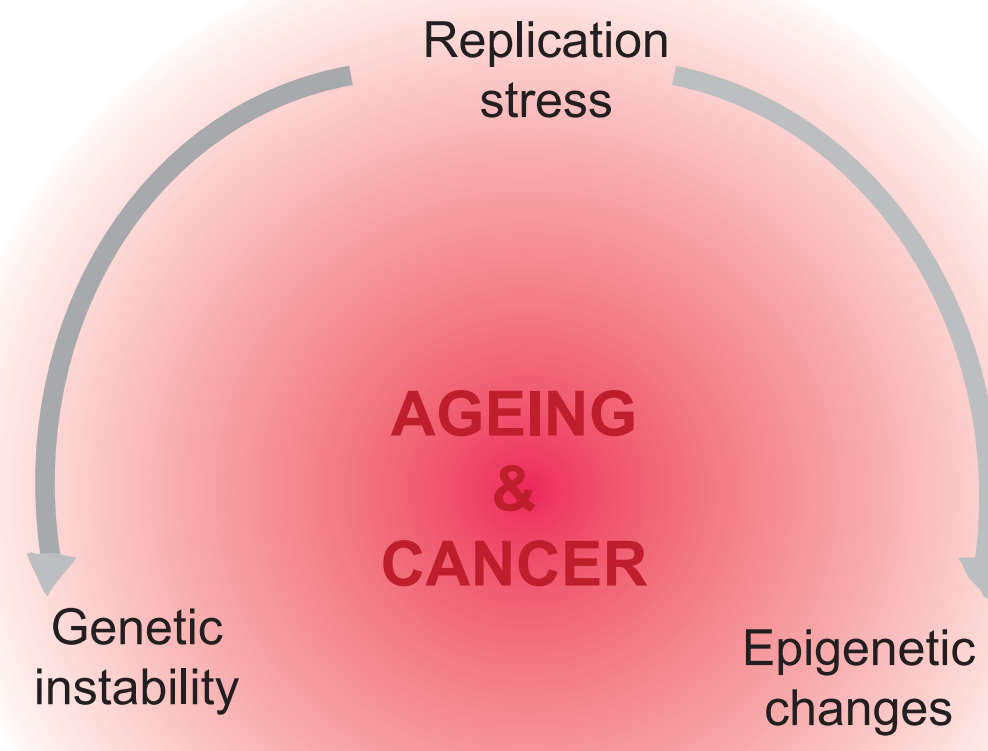

